OPEN ACCESS

Edited by:

Valery I. Shestopalov,

University of Miami, United States

Reviewed by:

Bela Volgyi,

University of Pécs, Hungary

Rheinallt Parri,

Aston University, Birmingham,

United Kingdom

*Correspondence:

Mathieu Charvériat

mathieu.charveriat@theranexus.com

Received: 15 April 2017 Accepted: 08 June 2017

Published: 26 June 2017

Citation:

Charvériat M, Naus CC, Leybaert L, Sáez JC and Giaume C (2017)

Connexin-Dependent Neuroglial

Networking as a New Therapeutic

Target. Front. Cell. Neurosci. 11:174.

doi: 10.3389/fncel.2017.00174

\section{Connexin-Dependent Neuroglial Networking as a New Therapeutic Target}

\author{
Mathieu Charvériat ${ }^{1 *}$, Christian C. Naus ${ }^{2}$, Luc Leybaert ${ }^{3}$, Juan C. Sáez ${ }^{4,5}$ and \\ Christian Giaume ${ }^{6}$
}

${ }^{1}$ Theranexus, Lyon, France, ${ }^{2}$ Department of Cellular and Physiological Science, Life Science Institute, University of British Columbia, Vancouver, BC, Canada, ${ }^{3}$ Physiology Group, Department of Basic Medical Sciences, Faculty of Medicine and Health Sciences, Ghent University, Ghent, Belgium, ${ }^{4}$ Departamento de Fisiología, Pontificia Universidad Católica de Chile, Santiago, Chile, ${ }^{5}$ Centro Interdisciplinario de Neurociencias de Valparaíso, Instituto Milenio, Valparaíso, Chile, ${ }^{6}$ Center of Interdisciplinary Research in Biology, Collège de France, Paris, France

Astrocytes and neurons dynamically interact during physiological processes, and it is now widely accepted that they are both organized in plastic and tightly regulated networks. Astrocytes are connected through connexin-based gap junction channels, with brain region specificities, and those networks modulate neuronal activities, such as those involved in sleep-wake cycle, cognitive, or sensory functions. Additionally, astrocyte domains have been involved in neurogenesis and neuronal differentiation during development; they participate in the "tripartite synapse" with both pre-synaptic and post-synaptic neurons by tuning down or up neuronal activities through the control of neuronal synaptic strength. Connexin-based hemichannels are also involved in those regulations of neuronal activities, however, this feature will not be considered in the present review. Furthermore, neuronal processes, transmitting electrical signals to chemical synapses, stringently control astroglial connexin expression, and channel functions. Long-range energy trafficking toward neurons through connexin-coupled astrocytes and plasticity of those networks are hence largely dependent on neuronal activity. Such reciprocal interactions between neurons and astrocyte networks involve neurotransmitters, cytokines, endogenous lipids, and peptides released by neurons but also other brain cell types, including microglial and endothelial cells. Over the past 10 years, knowledge about neuroglial interactions has widened and now includes effects of CNS-targeting drugs such as antidepressants, antipsychotics, psychostimulants, or sedatives drugs as potential modulators of connexin function and thus astrocyte networking activity. In physiological situations, neuroglial networking is consequently resulting from a two-way interaction between astrocyte gap junction-mediated networks and those made by neurons. As both cell types are modulated by CNS drugs we postulate that neuroglial networking may emerge as new therapeutic targets in neurological and psychiatric disorders.

Keywords: astrocyte network, connexin, gap junction, neuroglial interaction, glia 


\section{INTRODUCTION}

In the eighteenth century, the neuron doctrine asserted that nerve tissues are composed of functional units called neurons. The concept of neuroglia, the connective tissue in which nervous system elements were embedded, proposed by Rudolf Virchow by the end of the last century (Virchow, 1859), has at least four different sub-populations of glial cells identified in the central nervous system (Kettenmann and Verkhratsky, 2008). Among them, astrocytes were considered as having a high level of dynamic and integrative interactions with neurons. When electrophysiological properties of astrocytes were discovered, neuroglial interactions were firstly theorized. The occurrence of electrotonic and dye coupling between those cells were demonstrated in the late 80s (Kettenmann and Ransom, 1988), followed by the description of the structures and the molecular nature of GJs that connect astrocytes (Giaume et al., 1991a; Nagy and Rash, 2000). In the 90s, communication between astrocytes via $\mathrm{Ca}^{2+}$ waves were identified, as well as tuning of neuronal activity, leading to the first documentation of bidirectional communication between astrocytes and neurons, and descriptions of "tripartite synapses" associating a pre-synaptic neuron, a post-synaptic neuron and an astrocyte (Araque et al., 1999; Hubbard and Binder, 2016). Interestingly, one astrocyte can be connected to up to 140,000 synapses (Bushong et al., 2002); astrocytes are organized in plastic and tightly regulated networks (Giaume and Liu, 2012). The role of astrocytes in complex functions is further emphasized by the glia-to-neuron ratio that increases with the evolution toward more and more adapted organisms (Verkhratsky and Nedergaard, 2016). This review focuses on how astrocytes and neurons communicate, encompassing the extent and the modulation of astrocyte networking. We will specifically emphasize the role of astrocyte connexins (Cxs), transmembrane proteins involved in cell-cell communication through GJs, as the role of astrocytes Cxs as hemichannels has been recently reviewed (Giaume et al., 2013; Orellana and Stehberg, 2014).

\section{ASTROCYTE NETWORKS ARE FORMED BY GJS}

\section{Astrocyte GJs Are Encoded by Cx30 and Cx43}

Among the 11 Cxs detected in the rodent brain (Nagy et al., 2004), astrocytes express two major Cxs, $\mathrm{Cx} 43$, and $\mathrm{Cx} 30$, and possibly Cx26 (Perez Velazquez et al., 1996; Lynn et al., 2011; Wasseff and Scherer, 2011). In astrocytes, $\mathrm{Cx} 43$ is distributed in a plaque-like manner between cells and is also located elsewhere in these cells

\footnotetext{
Abbreviations: CNS, Central Nervous System; Cx, Connexin; EAAT, Excitatory Amino Acid Transporter; ER, Endoplasmic Reticulum; gapFRAP, GapFluorescence Recovery After Photobleaching; GJ, Gap Junction; GJC, gap junctional communication; GLUT1, Glucose Transporter type 1; GLUT3, Glucose Transporter type 3; HC, Hemichannel; IHC, Immunohistochemistry; $\mathrm{IP}_{3}$, Inositol trisphosphate; Kir1.4, Potassium inwardly-rectifying channel 1.4; LY, Lucifer Yellow; MCT1/4, Mono-Carboxylate Transporter 1/4; MCT2, Mono-Carboxylate Transporter 2 .
}

compatible with cytoplasmic pools or hemichannels. This $\mathrm{Cx}$ appears post-natally while Cx30 is expressed several weeks after birth (Kunzelmann et al., 1999). In primary cultures astrocytes express only Cx43 while Cx30 starts to be detected after 10 weeks, however, the addition of neurons induces expression of Cx30 in 3 week-old primary cultures (Koulakoff et al., 2008). Interestingly, Cx30/Cx30 and Cx43/Cx43 form functional homotypic channels, whereas heterotypic $\mathrm{Cx} 30 / \mathrm{Cx} 43$ do not (Orthmann-Murphy et al., 2007). In general, Cx43 is predominant, but its expression varies by brain region and stage of development (Nagy et al., 2004). For instance, hypothalamic astrocytes express four times more Cx43 than striatal astrocytes, and are more highly coupled (Batter et al., 1992). White matter astrocytes express minimal or no Cx30 (Nagy et al., 1999). In contrast, in the thalamus Cx30 is more highly expressed than Cx43 (Griemsmann et al., 2015). Coupling between astrocytes is greatly reduced in cells lacking Cx43 and abolished when both Cx43 and Cx30 are absent (Perez Velazquez et al., 1996; Naus et al., 1997; Wallraff et al., 2006; Rouach et al., 2008; Roux et al., 2011), demonstrating that these two Cxs are the main molecular support for direct intercellular communication in astrocytes.

\section{Regulation of GJs in Astrocytes}

Neurotransmitters and second messenger pathways regulate gap junctional communication between astrocytes for review see Giaume et al. (2010). In cultured astrocytes "dye-coupling" can be increased by extracellular application of glutamate or high $\mathrm{K}^{+}$solutions (Enkvist and McCarthy, 1994). Such $\mathrm{K}^{+}$-induced upregulation of gap junctional communication may involve the calmodulin kinase pathway (De Pina-Benabou et al., 2001). In the olfactory bulb (Roux et al., 2011) and the thalamus (Claus et al., 2016), gap junctional communication is controlled by neuronal activity and this regulation is due to Cx30 GJ channels (Roux et al., 2011). Glutamate or high $\mathrm{K}^{+}$solution causes membrane depolarization and this might be linked to changes in coupling via changes in intracellular $\mathrm{pH}$. Depolarization produces an alkaline shift in astrocytes that could enhance coupling (Ransom and Sontheimer, 1992). In addition, glutamate effects on gap junctional communication may contribute to neuronal activity-dependent control of $\mathrm{Cx} 43$ expression in astrocytes with important consequences for astrocyte coupling (Rouach et al., 2000). In contrast to the effect of neuronal activity, brain macrophages can reduce $\mathrm{Cx} 43$ expression in astrocytes (Rouach et al., 2002b; Faustmann et al., 2003). Other naturally occurring molecules, including endothelins (Blomstrand et al., 2004) and inflammatory cytokines (Duffy et al., 2000), have also been shown to downregulate $\mathrm{Cx}$ expression and function in astrocytes. These properties indicate that the extent of astroglial networks is under the control of a number of active compounds present in the brain, including neurotransmitters, which means that their size and probably their shape are plastic.

\section{Organization of Astrocyte Networks in Anatomo-Functional Units}

Interestingly, in brain areas characterized by a strong anatomofunctional organization, the network of coupled astrocytes 
follows such topographical organization. This is the case in layer IV of the somatosensory cortex, the so-called barrel cortex, where the distribution of $\mathrm{Cx} 43$ and $\mathrm{Cx} 30$ is enriched within the barrels compared to the inter-barrel space (Houades et al., 2008). This feature is also found for the intercellular communication since dye coupling experiments indicate that coupling is favored within the barrels, while astrocytes located in the septa are weakly coupled (Houades et al., 2008). Interestingly, such restricted networking has recently been found in the thalamus in the barreloid fields (Claus et al., 2016) that pertain to the same whisker sensory-motor pathway. Another study performed in the olfactory bulb has demonstrated that in the glomerular layer the expression of $\mathrm{Cx} 43$ and $\mathrm{Cx} 30$ is also increased in the glomeruli compared to the extraglomerular space and that the expression of the two Cxs is even segregated within the functional unit itself, $\mathrm{Cx} 43$ being more pronounced at the border of the glomeruli while $\mathrm{Cx} 30$ is rather detected into its center (Roux et al., 2011). These studies indicate that, at least in functional units, on the basis of $\mathrm{Cx}$ expression and channel function there is an overlap between neuronal circuitry and astroglial networking, suggesting strong correlations between local organization of astroglial networks and neuronal functions.

When considering glial networks two notions are important to take into account. First, not all astrocytes in a defined area are coupled together. This was reported in the hippocampus by performing dye coupling experiments in the eGFP-hGFAP mouse where it was observed that, in the coupling area defined by the intercellular spread of sulforhodamine B, several eGFP-positive astrocytes were excluded (Houades et al., 2006). Also in the olfactory bulb, olfactory ensheathing cells are reported to be preferentially coupled to a subset of their neighbors forming subdomains with the potential to affect specific axon fascicles (Rela and Szczupak, 2007). These observations suggest that astroglial networks, in addition to being plastic, do not involve all astrocytes of a considered location.

\section{Toward More Complex Networks}

Additionally, there is now evidence for a panglial networking between two types of glial cells. This was already reported from co-culture studies that established gap junction (G)-mediated communication between astrocytes and oligodendrocytes (Kettenmann and Ransom, 1988) and that this heterotypic coupling requires differentiated oligodendrocytes (Venance et al., 1995; Niu et al., 2016). More recently, brain slice studies indicated that, depending on the brain area considered, this panglial networking was present in the neocortex, the hippocampus, and the thalamus (Griemsmann et al., 2015). Such heterotypic coupling may also have important consequences on the role of glial GJs as for instance recently reported for the intercellular trafficking of metabolic substrates between astrocytes and differentiated oligodendrocytes (Niu et al., 2016), thus adding further complexity in neuroglial networking interactions.

\section{ASTROCYTE NETWORKS MODULATE NEURONAL ACTIVITIES}

As presented above and at least in specific brain areas, there is an overlap between neuronal circuitry and astroglial networking (Rela and Szczupak, 2007; Houades et al., 2008; Roux et al., 2011) or with the panglial networking (Claus et al., 2016). Such functional intersection can be correlated to the function of local astrocyte networks in complex cerebral functions, such as sleep-wake cycle regulation, and dysfunction (Franco-Perez et al., 2012), cognition (Dallerac and Rouach, 2016), behavior (Pannasch and Rouach, 2013), or sensory functions (Han et al., 2014).

\section{Roles of Astrocyte Networks as Modulators of Neuronal Activities}

Interestingly, astrocyte Cxs modulate adult neurogenesis in mice. Inactivation of $\mathrm{Cx} 43$ in astrocytes diminished neural progenitor proliferation and survival of new-born neurons, while ablation of Cx30 showed opposite effects (Liebmann et al., 2013). Moreover, it was shown that engrafting human astrocytes in recipient mice resulted in GJ-mediated coupling between host and engrafted astrocytes with a sharply enhanced long-term potentiation as well as their capacity for learning and memory (Han et al., 2013). More precisely, it was demonstrated that Cx43-mediated gap-junctional coupling between astrocytes is important in the neuron-glia interactions required for whisker-related sensory functions and plasticity. Indeed, mice with a knocked-down expression of $\mathrm{Cx} 43$ in astrocytes showed a reduction in their ability to sense the environment with their whiskers (Han et al., 2014).

Conversely, coupling-deficient astrocytes lead neurons to present a reduced threshold for the generation of epileptiform events (Wallraff et al., 2006). The role of astroglial networks for normal brain functions is also highlighted by impairments in sensorimotor and spatial memory tasks in double KO Cx43/Cx30 mice (Lutz et al., 2009), the modulation of exploratory and locomotor activity in $\mathrm{Cx} 43 \mathrm{KO}$ mice (Frisch et al., 2003; Theis et al., 2003) or the anxiogenic profile of $\mathrm{Cx} 30 \mathrm{KO}$ mice (Dere et al., 2003). Meanwhile, double KO Cx43/30 mice exhibit normal pain perception but do not present allodynia or hyperalgesia after spinal cord injury, contrary to simple KO Cx30 mice (Chen et al., 2012).

It was further shown by inactivating $\mathrm{Cx} 43$ and $\mathrm{Cx} 30$ that astroglial networks reduced synaptic transmission in hippocampal neurons (Pannasch et al., 2011). Additionally, GJmediated glial networks enable synaptic information transfer and limits the number of functional synapses, hence modulating the generation of neuronal network activities (Pannasch et al., 2012). In the end, astroglial networks were shown to modulate neuronal depolarization, release probability, and recruitment during bursting (Chever et al., 2016). Altogether, those experiments largely contribute to the hypothesis that $\mathrm{Cx}$ expression in astrocytes can contribute to modulate neuronal functions and synchrony. 


\section{How Do Astrocyte Networks Tune Neuronal Functions?}

To test whether astrocyte networks contribute to glutamatergic synaptic activity, neuronal activity during exogenous glucose deprivation was monitored in mice. Lactate and glucose were demonstrated to be trafficked through astrocyte networks in the hippocampus and further used by neurons as an energetic substrate to sustain their excitatory activity. This directly suggests that astroglial networks are involved in energetic metabolite trafficking from astrocytes to neurons (Rouach et al., 2008; see Figure 1).

It has also been demonstrated that double $\mathrm{Cx} 43-\mathrm{Cx} 30$ KO mice have increased hippocampal synaptic transmission, and impaired long-term synaptic plasticity. Indeed, astrocyte GJs facilitate extracellular glutamate and potassium ion $\left(\mathrm{K}^{+}\right)$removal during neuronal activity (see Figure 2). Synaptic function is hence limited and controlled by astrocyte networks, through the impact on extracellular homeostasis notably on glutamate and $\mathrm{K}^{+}$(Wallraff et al., 2006; Pannasch et al., 2011). Moreover, it was described that Cx30 controlled the setting of excitatory synaptic strength, justifying the role it plays in long-term synaptic plasticity and in hippocampus-based contextual memory (Pannasch et al., 2014).

Finally, $\mathrm{Ca}^{2+}$ signaling in astroglial networks can trigger glutamate release and hence neuron depolarization and firing (Kang et al., 2005), synchronize neuronal activities (Poskanzer and Yuste, 2011, 2016) and underlie hippocampal synaptic plasticity involved in learning and memory (Serrano et al., 2006). Additionally, in mice grafted with human astrocytes, intercellular $\mathrm{Ca}^{2+}$ waves were three-time faster than in normal conditions, and basal transmission and synaptic plasticity were enhanced, pointing the role of those waves in neuronal control (Han et al., 2014).

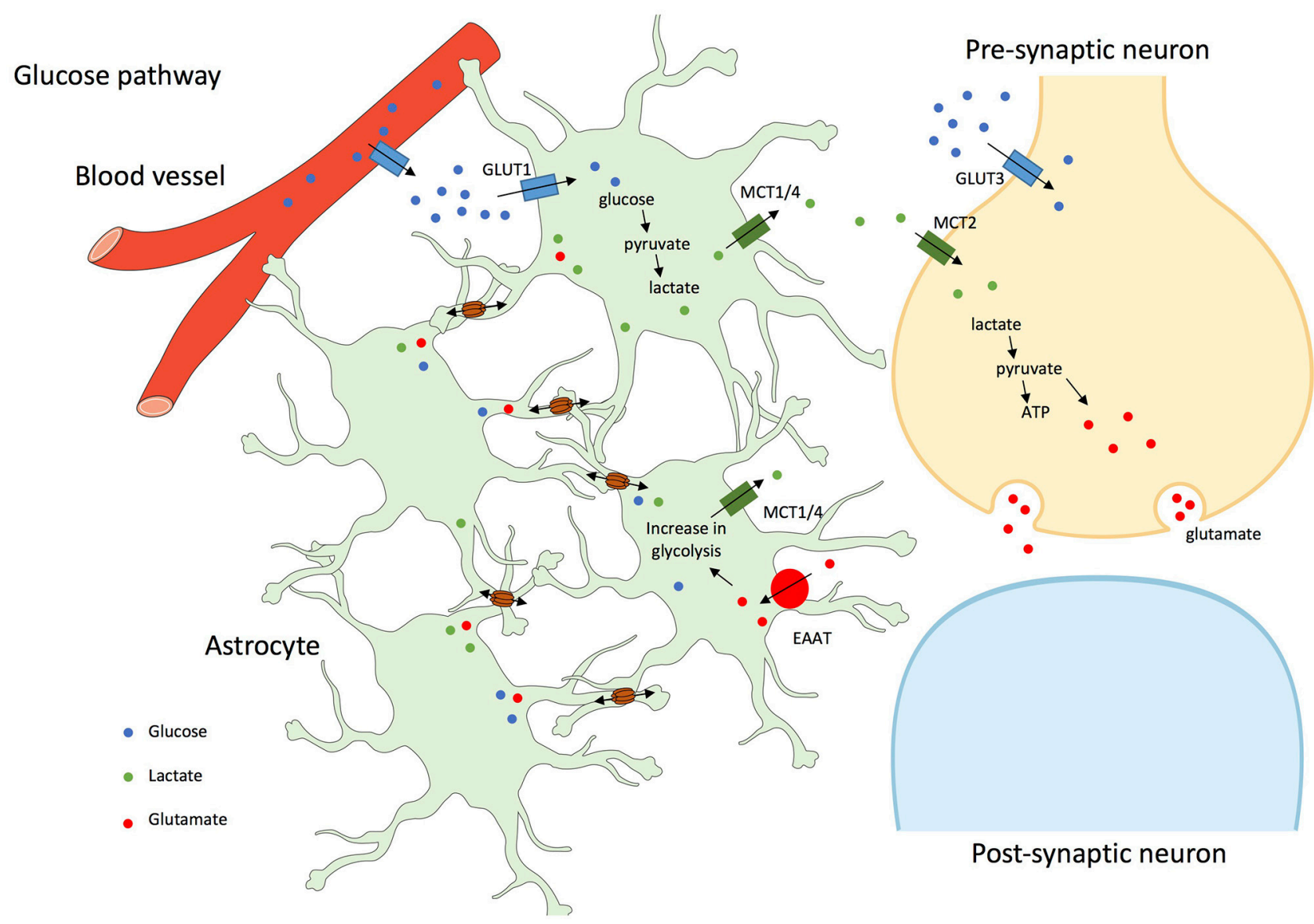

FIGURE 1 | Glucose and glutamate pathways in astrocyte networks and interactions with neurons. In addition to a direct pathway to neurons by the extracellular space, glucose from blood vessels is taken-up through astrocytic end-feet or through GLUT1 (Glucose transporter 1) facilitated transport, and by neurons through GLUT3 (Glucose transporter 3) transport. In astrocytes, glucose is metabolized to lactate, which is exported through MCT1/4 (Mono-Carboxylate Transporter 1/4); lactate is shuffled into neurons by MCT2 (Mono-Carboxylate Transporter 2) and participates in the synthesis of glutamate, further stored in vesicles until exocytotic release. After neuronal firing, glutamate released into the synaptic cleft is removed by astrocytes through EAAT (Excitatory Amino Acid Transporter) and recycled as glutamine. This glutamate-glutamine cycling and the associated sodium entry consumes energy, which drives astrocytic glycolysis and results in lactate production (Pellerin et al., 2007). Glucose, lactate, and glutamate are transferred between connected astrocytes through GJs (Cx30 and Cx43; Leybaert, 2005; Orellana et al., 2009; Escartin and Rouach, 2013). 


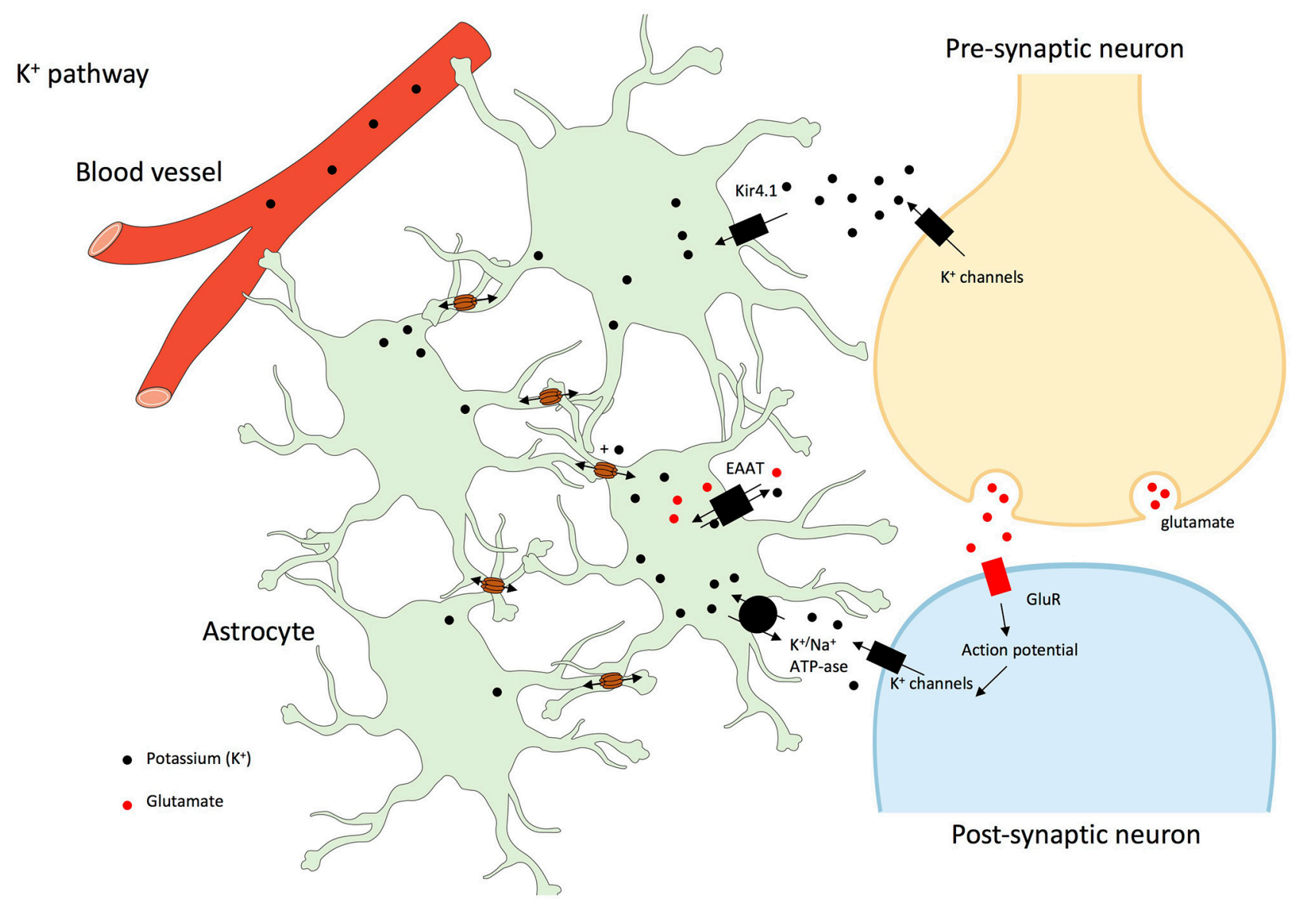

FIGURE 2 | $\mathrm{K}^{+}$pathway in astrocyte networks and interactions with neurons. Gap junctions play a central role in the dissipation of $\mathrm{K}^{+}$and its spatial buffering by astrocytes. Indeed, glial networking disperses local extracellular $\mathrm{K}^{+}$increases by transferring $\mathrm{K}^{+}$from sites of elevated concentrations to sites of lower concentrations through gap junctions. Potassium ions are taken-up through Kir1.4 (Potassium inwardly-rectifying channel 1.4), EAAT or K+/Na ${ }^{+}$-ATP-ase (Rouach et al., 2000, 2004, 2008; Kofuji and Newman, 2004; Giaume et al., 2010; Pannasch and Rouach, 2013). In addition, at least in olfactory glomeruli, high external $\mathrm{K}^{+}$concentrations increases Cx30-mediated intercellular coupling which facilitates $\mathrm{K}^{+}$buffering by astroglial networks (Roux et al., 2011).

While in the hippocampus Cx30 and Cx43 each contribute to approximately half of the astroglial communication (Rouach et al., 2008), they play different roles in terms of neuronal modulation (Dere et al., 2003; Frisch et al., 2003; Theis et al., 2003; Lutz et al., 2009; Roux et al., 2011; Chen et al., 2012), as recently reviewed (Pannasch and Rouach, 2013). Nevertheless, data are in favor of a role of astroglial network control of neurons through at least spatial $\mathrm{K}^{+}$buffering, glutamate clearance, and energy metabolite trafficking, potentially mediated by the spreading of astrocyte activation by cell-to-cell propagating intercellular $\mathrm{Ca}^{2+}$ waves (see Figure 3).

\section{NEURONAL ACTIVITY REGULATES ASTROCYTE NETWORKS}

Neuronal activity is modulated by astrocyte networks as described above, but the opposite, i.e., a tight control of astroglial Cxs by neurons, has also been amply documented the literature (Rouach et al., 2004; Giaume et al., 2010).

\section{Evidence for Regulation of Astroglial Networks by Neurons}

Neurotransmitters can either increase or decrease the strength of GJ coupling depending on the receptor subtypes that are involved (Giaume and McCarthy, 1996), for instance noradrenaline (Giaume et al., 1991b), glutamate (Enkvist and McCarthy, 1994; Muller et al., 1996), NMDA/acetylcholine (Rouach et al., 2002c), or serotonin (Moore and Burt, 1995) modulate Cx43 gap junctional communication (GJC).

There is strong evidence that neurons upregulate GJC. Indeed, experimental work has indicated that in co-cultures the presence of neurons largely enhanced astroglial coupling via Cxs (Rouach et al., 2000; Koulakoff et al., 2003, 2008). This effect was attributed to astrocyte differentiation by diffusible factors from neurons (Fischer and Kettenmann, 1985). Cellular coupling enhancement depends on the age and density of neurons, as neuronal maturation is required to observe the increase (Rozental et al., 1998; Rouach et al., 2000). Similarly, neuronal injury leads to an increase of GJC in co-cultured 


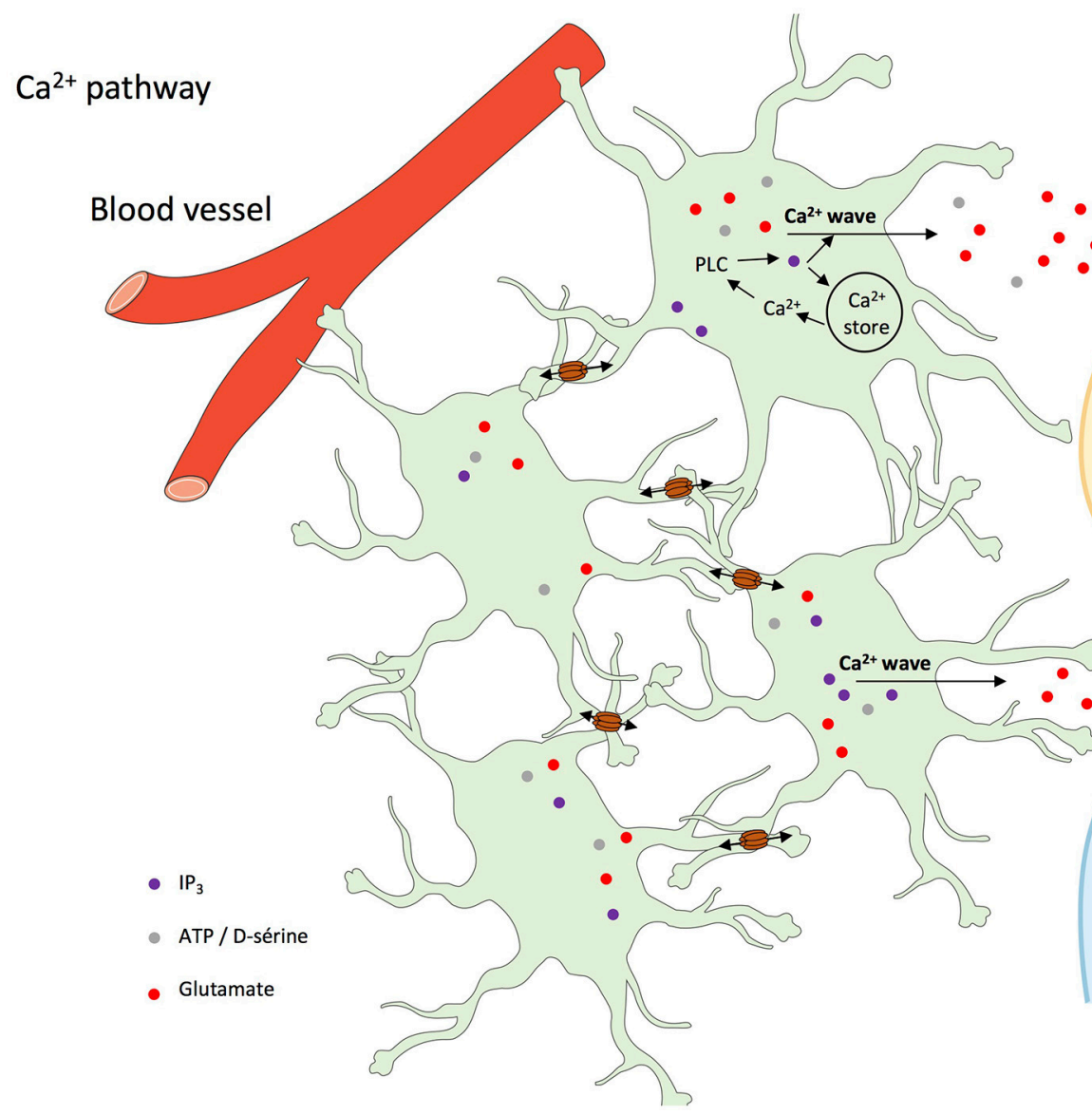

\section{Pre-synaptic neuron}

pathway

FIGURE 3 | Intercellular $\mathrm{Ca}^{2+}$ waves in astrocyte networks and interactions with neurons. The rise of intracellular $\mathrm{Ca}^{2+}$ concentration in astrocytes usually involves the activation of G-protein-coupled receptors, activation of phospholipase C (PLC), and the production of inositol trisphosphate $\left(\mathrm{IP}_{3}\right)$, which leads to $\mathrm{Ca}^{2+}$ release from the endoplasmic reticulum (ER). Elevation of cytoplasmic $\mathrm{Ca}^{2+}$ concentration further affects several plasma membrane proteins, such as metabotropic receptors, $\mathrm{K}^{+}$and $\mathrm{Ca}^{2+}$ channels, $\mathrm{Na}^{+} / \mathrm{Ca}^{2+}$ exchanger, and $\mathrm{Ca}^{2+}$-ATPase. Once triggered, intracellular $\mathrm{Ca}^{2+}$ waves can be transmitted as intercellular $\mathrm{Ca}^{2+}$ waves to neighboring cells through the diffusion of inositol trisphosphate $\left(\mathrm{I}_{3}\right)$ production and $\mathrm{Ca}^{2+}$ through gap junctions, and subsequent release of $\mathrm{Ca}^{2+}$ from the endoplasmic reticulum (Cotrina et al., 1998; Leybaert et al., 1998; Scemes et al., 1998; Scemes and Giaume, 2006; Leybaert and Sanderson, 2012; De Bock et al., 2014). $\mathrm{Ca}^{2+}$-dependent release of gliotransmitters then target neuronal receptor but also astroglial receptors that participate to and amplify the process of propagation of intercellular $\mathrm{Ca}^{2+}$ waves (Scemes and Giaume, 2006).

astrocytes (Anders and Woolery, 1992) or in astrocytes in situ (Rohlmann et al., 1993; Hanani et al., 2002). Additionally, nerve stimulation increases gap junctional communication (Marrero and Orkand, 1996) and dephosphorylates Cx43 in astrocytes (Li and Nagy, 2000).

On the opposite, the stimulatory effect of neurons on astroglial GJC was prevented in several conditions in which neuronal functions were altered, as after treatment with TTX, used to inhibit neuronal spontaneous activity (Muller et al., 1996; Rouach et al., 2008; Serrano et al., 2008; Roux et al., 2011). For instance, distant TTX infusion in Schäffer collaterals reduces the diffusion of a fluorescent glucose analog through astrocyte gap junctions in the stratum oriens by up to $35 \%$, while the diffusion of passive dyes is not affected (Rouach et al., 2008). However, in the thalamus where $\mathrm{Cx} 30$ expression prevails in astrocytes, TTX reduces gap junction permeability for both types of molecules (Claus et al., 2016). In addition in the olfactory bulb where Cx30 also prevails, TTX or sensory deprivation also blocks plasticity of astrocyte networks in the rodent olfactory glomeruli (Roux et al., 2011).

\section{Cx30 and Cx43, Major Determinants of Astrocyte Network Plasticity Induced by Neuronal Activity}

In the hippocampus, the regulation of astroglial networking by neurons is not observed with passive fluorescent dyes, indicating that neuronal activity does not directly regulate GJ permeability but rather triggers neuronal energetic demand through astrocyte gap junctions (Rouach et al., 2008). As indicated above, astrocytes are mainly coupled with $\mathrm{Cx} 30$ - and $\mathrm{Cx} 43$-forming junctional plaques (Rouach et al., 2002a, 2004; Koulakoff et al., 2008). Interestingly, in cell cultures, neurons up-regulate the expression of $\mathrm{Cx} 43$; they also induce Cx30 expression in astrocytes located 
in proximity to neuronal somata. In $\mathrm{Cx} 43$-lacking astrocytes, the induction of $\mathrm{Cx} 30$ by neuronal presence allows the restoration of functional gap junctional communication mediated by $\mathrm{Cx} 30$ (Koulakoff et al., 2008). Additionally, in olfactory bulb acute slices, modulation of GJC by neuronal activity is still present in $\mathrm{Cx} 43 \mathrm{KO}$ but not in $\mathrm{Cx} 30 \mathrm{KO}$ mice. This indicates that in glomerular areas (i) $\mathrm{Cx} 43$-formed channels are insensitive to neuronal activity, and (ii) Cx30-formed channels are the molecular target of neuron-dependent modulation of astrocyteastrocyte communication (Roux et al., 2011). Interestingly, a recent study indicates that in the thalamus dye coupling in glial networks is also dependent on neuronal activity (Claus et al., 2016). In this structure Cx30 is also predominant (Griemsmann et al., 2015), as in the olfactory bulb, which reinforces the idea that the regulation of this $\mathrm{Cx}$ is the target for the neuronal control of glial networks.

Several mechanisms have been proposed to mediate neuronal induced up-regulation of gap junctional communication. Depolarization mediated by activity-dependent $\mathrm{K}^{+}$release has been demonstrated to enhance GJ coupling in astrocytes (Enkvist and McCarthy, 1994; Roux et al., 2011), with the participation of CAMKII-dependent phosphorylation of $\mathrm{Cx} 43$ (De Pina-Benabou et al., 2001). Glutamate is also a mediator of this modulation, however with confounding results depending on the involved receptor subtypes (Giaume, 2010; Giaume et al., 2010; Escartin and Rouach, 2013).

\section{Why Are Astrocyte Networks Plastic upon Neuronal Activity?}

Hence, continuous interactions between neurons and astrocytes are required to maintain high levels of $\mathrm{Cx}$ expression and function in astrocytes (Koulakoff et al., 2008; Rouach et al., 2008). Collectively, these data indicate that the size of the astroglial metabolic network is enlarged as overall neuronal activity increases, and reduced while neuronal activity diminishes or is abolished (see Table 1).

Astrocytes take-up glucose from blood flow, and glucose can be stored as glycogen and/or metabolized into lactate that can be released to neurons to fuel their tricarboxylic acid cycle. They provide local supply of energy substrates to neuronal surroundings (Magistretti, 2006; Pellerin et al., 2007; Belanger et al., 2011). Astrocytes are organized in plastic networks: those networks are confined to specific places as described in glomerular structures, where intraglomerular astrocytes are mainly coupled within the limits of a single glomerulus (Roux et al., 2011) within rodent barrels in the somatosensory cortex (Houades et al., 2006) and the barreloids in the thalamus (Claus et al., 2016). Such confinement potentially favors specific neuron-astrocyte interactions at a network level in physiological processes. As presented above, astrocyte networks are tightly regulated and gated by neuronal activity. Concerning the metabolic networking, this regulation involves glutamatergic signaling by AMPA receptors. Thus, it can be inferred that plasticity of the astroglial networking may result from an adaptation to neuronal demand, to reach more efficiently and distally the sites of high neuronal demand. Such a hypothesis has notably been established in specific areas of the hippocampus, in which neuronal activity changes the shape and extent of astroglial networks (Rouach et al., 2008).

\section{ASTROGLIAL CXS AND BRAIN PHARMACOLOGICAL AGENTS}

Drugs used to treat neurological and psychiatric disorders are generally studied through their neuronal effects. It is now clear that astrocytes are also targeted by those drugs, especially through the modulation of $\mathrm{Cx} 30$ and $\mathrm{Cx} 43$ levels of expression and function, those modulations are either neuron-dependent or not dependent upon neuronal activities (see Table 2), and might be linked to the aforementioned reciprocal interactions between neurons and astrocyte networks.

\section{Diverse Effects of Antidepressants on Astroglial Cxs}

Amitriptyline, a tricyclic antidepressant widely used in neuropathic pain (Finnerup et al., 2015), significantly upregulates $\mathrm{Cx} 43$ mRNA, protein and GJ channel function in astrocyte cultures. This up-regulation is not related to monoamines as noradrenaline, serotonin, and dopamine did not induce $\mathrm{Cx} 43$ expression. It is suggested that this mechanism depends on $\mathrm{Cx} 43$ phosphorylation through an increase of p38 MAPK activity by amitriptyline (Morioka et al., 2014). These results have been recently challenged (Jeanson et al., 2016a,b), as Cx43 GJs were inhibited (instead of promoted) by lower doses of amitriptyline than those used by Morioka et al. (2014). Possibly microglial cells may contribute to these distinct responses of GJ coupling to different doses of amitriptyline. Indeed, the number and activation status of microglial cells has been reported to interfere with $\mathrm{Cx} 43$ expression and function in astrocytes (Faustmann et al., 2003; Rouach et al., 2004; Même et al., 2006; Retamal et al., 2007).

Additionally, other studies have pointed out how tricyclic antidepressants such as clomipramine and imipramine modulate astrocyte Cx expression or functions (Morioka et al., 2014; Jeanson et al., 2016b). Of particular interest is the finding that $\mathrm{Cx}$ expression in astrocytes is modulated in animal models of depression as well as in depressed patients (Miguel-Hidalgo et al., 2014; Quesseveur et al., 2015; Nagy et al., 2017). Using relevant in vivo models (Hamon et al., 2008; M'Dahoma et al., 2015), it was demonstrated that mefloquine-at doses which do not affect neuropathic pain symptoms-significantly enhances the effects of amitriptyline on neuropathic pain (Jeanson et al., 2016a). Those data suggest a central role of astroglial Cxs as modulators of the pharmacological profile of antidepressants.

The analysis of others classes of antidepressants such as SNRI (Serotonin-Norepinephrine Reuptake Inhibitor), NRI (Norepinephrine Reuptake Inhibitor), and SSRI (Selective Serotonin Reuptake Inhibitor) has shown contrasting effects after treatment of astrocyte cultures (Sun et al., 2012; Morioka et al., 2014; Mostafavi et al., 2014; Jeanson et al., 2016b). 

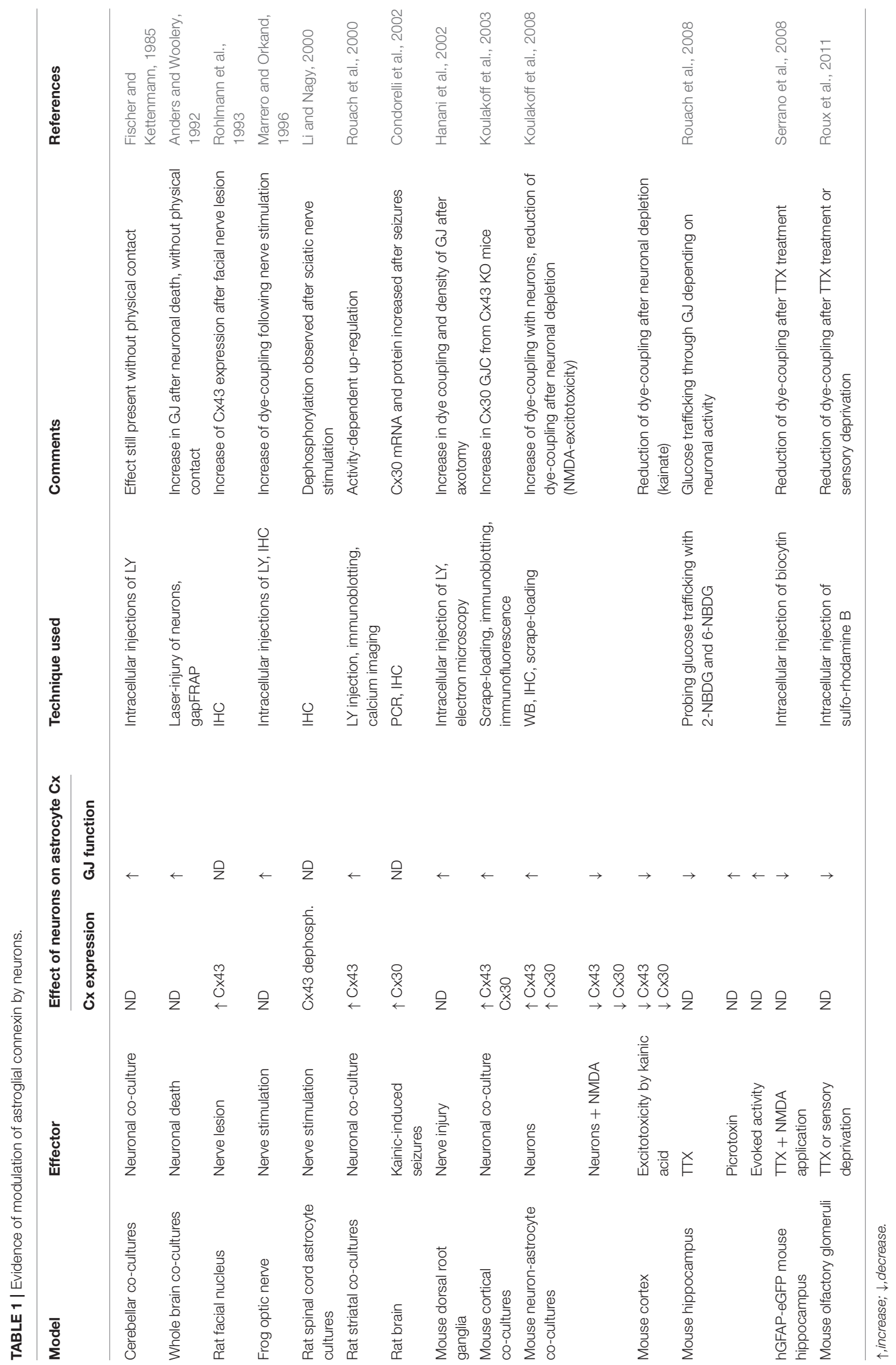


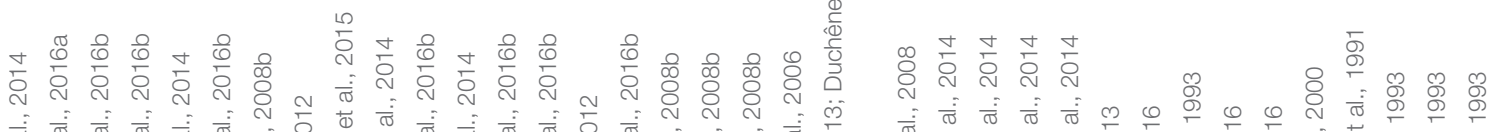

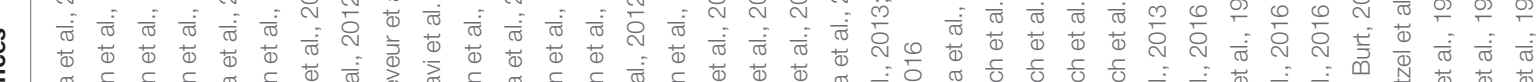

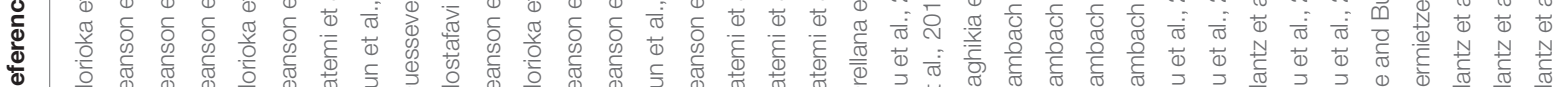
焉

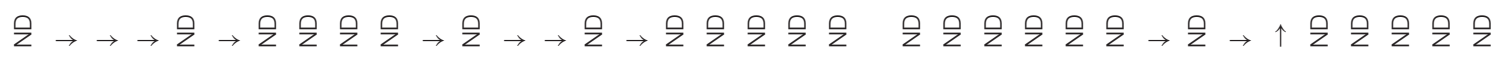

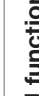

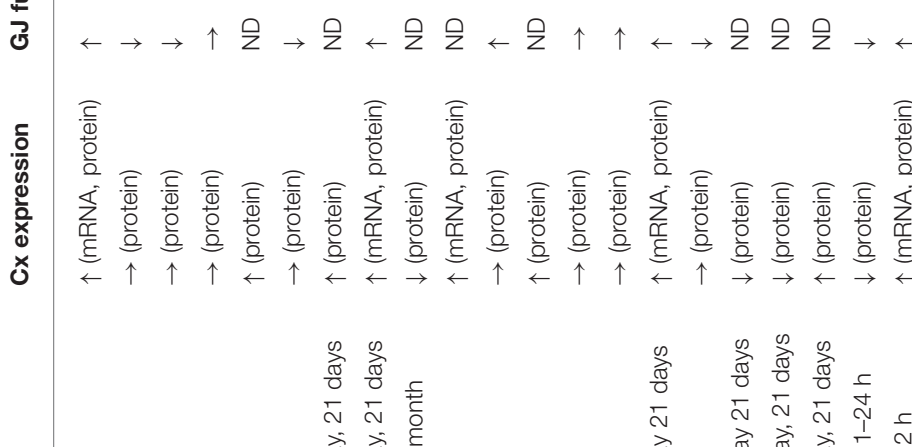

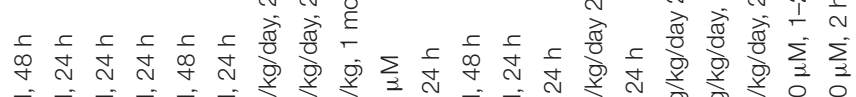

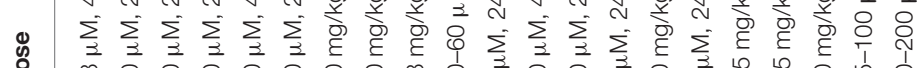

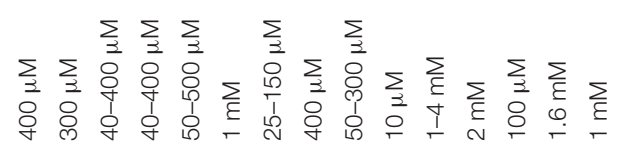
ه.

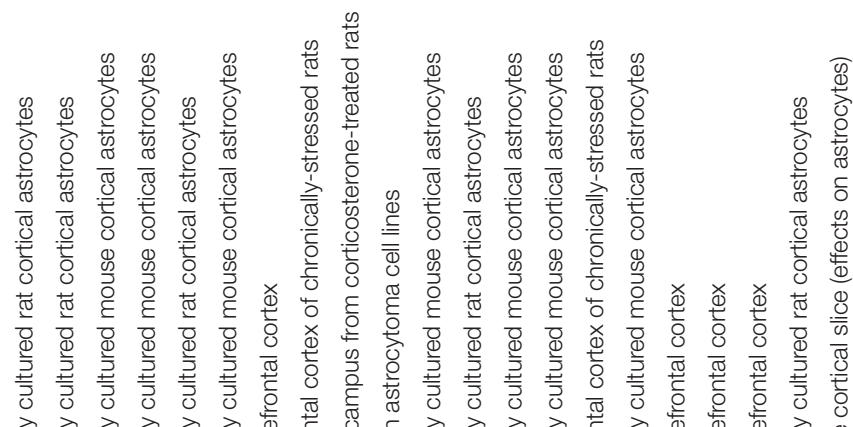

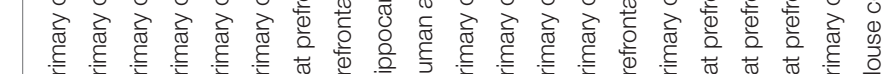
$\leftarrow$ १ १ १ $\rightarrow \rightarrow \rightarrow \rightarrow \rightarrow \rightarrow \rightarrow \rightarrow \rightarrow \rightarrow$ 0

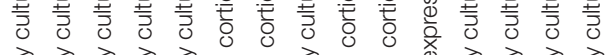

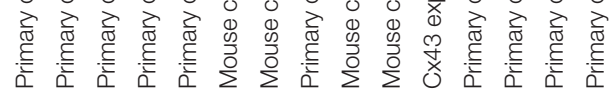

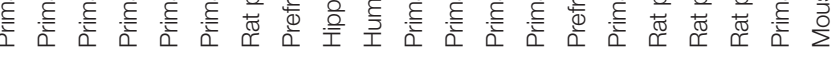


Interesting data have been gathered from antidepressant-treated rodents: chronic treatment with fluoxetine (SSRI) increased Cx43 expression in rat prefrontal cortex (Fatemi et al., 2008b). Consistently, it has been shown that stressed rats presented a lower level of $\mathrm{Cx} 43$ expression and function in the cortex, while fluoxetine reversed those reductions (Sun et al., 2012). Alternatively, it has been proposed that antidepressants such as fluoxetine may exert their therapeutic activity by decreasing the expression and/or activity of $\mathrm{Cx} 43$ in astrocytes, resulting from a lower level of phosphorylation, in the hippocampus (Quesseveur et al., 2015). Those results emphasize the complex effects of different therapeutic classes of antidepressants on astroglial Cxs, with various outcomes on expression and GJ and hemichannel functions as well as regional properties.

\section{Astroglial Cxs and Wake- or Sleep-Promoting Drugs}

The effects of numerous anesthetics on astroglial Cxs have been described for more than 20 years, notably in primary cultured astrocytes from the striatum or the cortex (Dermietzel et al., 1991; Mantz et al., 1993) or in astrocytes from cortical slices (Liu et al., 2013, 2016). Anaesthetics, either modulating
GABA $_{\mathrm{A}}$ [halothane (Dermietzel et al., 1991; He and Burt, 2000), enflurane, isoflurane, or propofol (Mantz et al., 1993)], $\mathrm{GABA}_{B}$ receptors [sodium oxybate (Liu et al., 2013)], or NMDA (ketamine; Liu et al., 2016) or $\alpha 2$-adrenergic receptors (dexmedetomidine; Liu et al., 2016), show similar profiles, as they reduced astroglial GJ. Conversely, modafinil, a wakepromoting drug widely used in narcolepsy (Barateau et al., 2016) with a complex mechanism of action (Minzenberg and Carter, 2008), enhances astroglial $\mathrm{Cx}$ and more precisely $\mathrm{Cx} 30$ expression and GJ function (Liu et al., 2013). Additionally, when astrocyte Cxs are inhibited by a new blocker, flecainide (Picoli et al., 2012), the wake-promoting and pro-cognitive activity of modafinil is largely enhanced in rodent models. This effect likely depends on the reversion by flecainide of Cx30-dependent modafinil up-regulation of gap junctional coupling in astroglial networks. Surprisingly, GJ modulation by flecainide also modulates effects of modafinil on cataplexy, a pathognomonic symptom of narcolepsy, underlining once again the central role of astroglial Cx in complex behaviors (Duchêne et al., 2016).

Altogether, those data reinforce the role that astrocytes play as controllers of sleep rhythm (Fellin et al., 2012) and complex

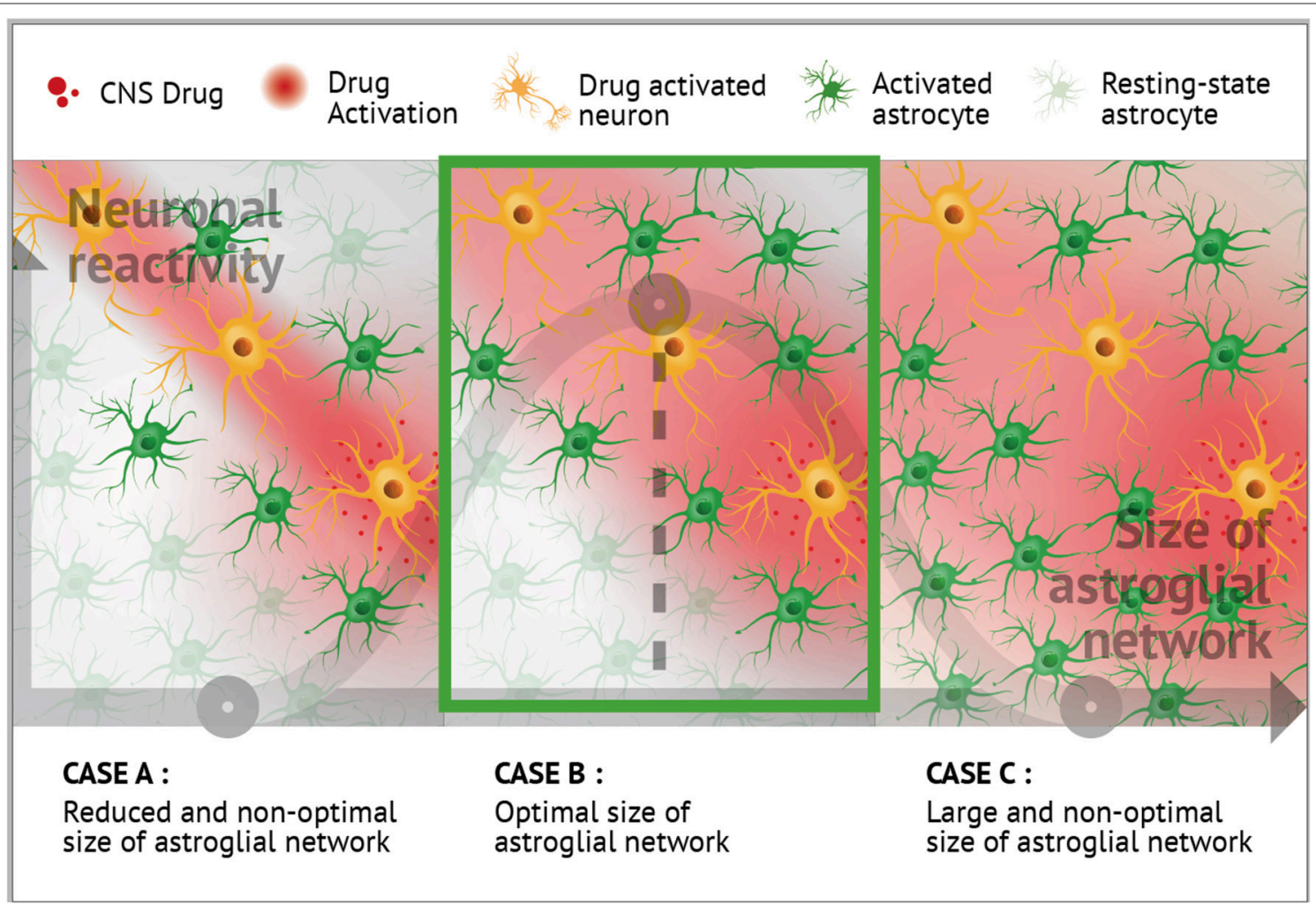

FIGURE 4 | Putative role of astroglial connexins in the modulation of the CNS drug profiles. Neuronal and astrocyte networking activities are mutually regulated. Neuronal activity leads to an up-regulation of astrocyte Cx expression and channel function (Rouach et al., 2000, 2004, 2008; Koulakoff et al., 2008; Giaume et al., 2010; Pannasch et al., 2011, 2012, 2014; Roux et al., 2011). Interestingly, certain CNS-targeting drugs also appear to impact astrocyte Cxs (Giaume and Liu, 2012; Liu et al., 2013, 2016; Duchêne et al., 2016; Jeanson et al., 2016a,b). As presented in the three panels and based on literature, it can be hypothesized that optimal neuronal reactivity could be associated with an optimal size of local astroglial network (B), as too large (C) or too reduced (A) syncytium might not adequately fuel metabolically active synapses during treatment with CNS drugs. Including aspects of drug action at the level of astrocytes, and more generally at the level of glial cells, opens up new avenues for potentially novel therapeutic applications. 
cognitive processes such as sleep (Franco-Perez et al., 2012), through the modulation of their network organization (Petit and Magistretti, 2016).

\section{Confounding Effects of Antipsychotics and Anti-Epileptics}

Psychiatric disorders such as schizophrenia, bipolar disorders, or autism are characterized by marked signs of glial dysfunction (Yamamuro et al., 2015). More precisely, in autistic patients astroglial Cx43 expression is increased in superior frontal cortex (Fatemi et al., 2008a). Antipsychotic drugs have been developed since the 50s to reduce the symptoms of those disorders, and among them haloperidol, lithium, clozapine, or chlorpromazine. Those drugs generally reduce the expression of astrocyte Cxs (Orellana et al., 2006; Fatemi et al., 2008b). Concerning chlorpromazine, kinetic studies indicate that this reduction is achieved through an indirect mechanism involving a complex signaling cascade from drug application to effects on GJ channels, including modulation by altered $\mathrm{Cx} 43$ phosphorylation. Alternatively, a cellular redistribution of GJs by chlorpromazine has also been suggested to be at the origin of the reduction of Cx43 levels (Orellana et al., 2006). Astrocyte Cxs are also involved in the pathophysiology of epilepsy (Steinhauser et al., 2016), as they are often up-regulated in this pathology. In line with this, their blockade is considered to act in an anticonvulsant manner; however, opposite (pro-convulsing) effects have also been reported (Carlen, 2012). Anti-epileptic drugs (valproic acid, carbamazepine, phenytoin, or gabapentin) generally do not modulate $\mathrm{Cx}$ expression (Dambach et al., 2014). However, levetiracetam enhances the expression of $\mathrm{Cx} 43$ and function of GJ in astrocyte-microglia mixed cultures, allegedly through an anti-inflammatory process (Haghikia et al., 2008). Finally, the effect of anti-epileptic drugs are also known to have an effect on neuronal Cxs (Mylvaganam et al., 2014) but this is beyond the scope of the present review.

\section{REFERENCES}

Anders, J. J., and Woolery, S. (1992). Microbeam laser-injured neurons increase in vitro astrocytic gap junctional communication as measured by fluorescence recovery after laser photobleaching. Lasers Surg. Med. 12, 51-62. doi: 10.1002/lsm.1900120110

Araque, A., Parpura, V., Sanzgiri, R. P., and Haydon, P. G. (1999). Tripartite synapses: glia, the unacknowledged partner. Trends Neurosci. 22, 208-215. doi: 10.1016/S0166-2236(98)01349-6

Barateau, L., Lopez, R., and Dauvilliers, Y. (2016). Treatment options for narcolepsy. CNS Drugs 30, 369-379. doi: 10.1007/s40263-016-0337-4

Batter, D. K., Corpina, R. A., Roy, C., Spray, D. C., Hertzberg, E. L., and Kessler, J. A. (1992). Heterogeneity in gap junction expression in astrocytes cultured from different brain regions. Glia 6, 213-221. doi: 10.1002/glia.440060309

Belanger, M., Allaman, I., and Magistretti, P. J. (2011). Brain energy metabolism: focus on astrocyte-neuron metabolic cooperation. Cell Metab. 14, 724-738. doi: 10.1016/j.cmet.2011.08.016

Blomstrand, F., Venance, L., Siren, A. L., Ezan, P., Hanse, E., Glowinski, J., et al. (2004). Endothelins regulate astrocyte gap junctions in rat hippocampal slices. Eur. J. Neurosci. 19, 1005-1015. doi: 10.1111/j.0953-816X.2004. 03197.x

\section{CONCLUSION}

Astrocytes are highly connected by $\mathrm{Cx} 30$ and $\mathrm{Cx} 43$, and this cell-cell communication strongly depends on neuronal activity. Conversely, neuronal processes are tightly tuned by astrocyte networks. The implications of neuroglial networking have furthermore been dissected in cognition, sleep-wake cycle, and sensory functions. Over the last decade, drugs that typically target neurons, such as antidepressant, antipsychotics, antiepileptic, psychostimulants, or anesthetics, have been shown to also modulate astroglial $\mathrm{Cx}$ expression and function. Additionally, reciprocal interactions, as well as mutual controls operate between neurons and Cx-formed astrocyte networks. Consequently, we envision that neuroglial networking may emerge as a new therapeutic target in neurological and psychiatric disorders. Two demonstrations of the interest in such targeting have been recently published in neuropathic pain (Jeanson et al., 2016a) and narcolepsy (Duchêne et al., 2016; $\mathrm{Lu}$ and Chen, 2016; see also Naus and Giaume, 2016). We hypothesized that astrocyte network size and structure should be adapted and optimized to neuronal demand, as a neither too large nor too reduced syncytium might adequately fuel metabolically active synapses, and this remains valid in the presence of CNS drugs (see Figure 4).

\section{AUTHOR CONTRIBUTIONS}

All authors listed, have made substantial, direct and intellectual contribution to the work, and approved it for publication.

\section{FUNDING}

This work was supported by Theranexus Company and the ANR (Projet NarConX, 14-CE16-0022) and Iniciativa Científica Milenio-Economía P09-022-F. CN holds a Canada Research Chair in Gap Junctions and Neurological Disorders.

Bushong, E. A., Martone, M. E., Jones, Y. Z., and Ellisman, M. H. (2002). Protoplasmic astrocytes in CA1 stratum radiatum occupy separate anatomical domains. J. Neurosci. 22, 183-192.

Carlen, P. L. (2012). Curious and contradictory roles of glial connexins and pannexins in epilepsy. Brain Res. 1487, 54-60. doi: 10.1016/j.brainres.2012.06.059

Chen, M. J., Kress, B., Han, X., Moll, K., Peng, W., Ji, R. R., et al. (2012). Astrocytic CX43 hemichannels and gap junctions play a crucial role in development of chronic neuropathic pain following spinal cord injury. Glia 60, 1660-1670. doi: $10.1002 /$ glia.22384

Chever, O., Dossi, E., Pannasch, U., Derangeon, M., and Rouach, N. (2016). Astroglial networks promote neuronal coordination. Sci. Signal. 9:ra6. doi: 10.1126/scisignal.aad3066

Claus, L., Philippot, C., Griemsmann, S., Timmermann, A., Jabs, R., Henneberger, C., et al. (2016). Barreloid borders and neuronal activity shape panglial gap junction-coupled networks in the mouse thalamus. Cereb. Cortex. doi: 10.1093/cercor/bhw368. [Epub ahead of print].

Condorelli, D. F., Mudo, G., Trovato-Salinaro, A., Mirone, M. B., Amato, G., and Belluardo, N. (2002). Connexin-30 mRNA is up-regulated in astrocytes and expressed in apoptotic neuronal cells of rat brain following kainate-induced seizures. Mol. Cell. Neurosci. 21, 94-113. doi: 10.1006/mcne.2002.1155 
Cotrina, M. L., Lin, J. H., Alves-Rodrigues, A., Liu, S., Li, J., Azmi-Ghadimi, H., et al. (1998). Connexins regulate calcium signaling by controlling ATP release. Proc. Natl. Acad. Sci. U.S.A. 95, 15735-15740. doi: 10.1073/pnas.95.26.15735

Dallerac, G., and Rouach, N. (2016). Astrocytes as new targets to improve cognitive functions. Prog. Neurobiol. 144, 48-67. doi: 10.1016/j.pneurobio.2016.01.003

Dambach, H., Hinkerohe, D., Prochnow, N., Stienen, M. N., Moinfar, Z., Haase, C. G., et al. (2014). Glia and epilepsy: experimental investigation of antiepileptic drugs in an astroglia/microglia co-culture model of inflammation. Epilepsia 55, 184-192. doi: 10.1111/epi.12473

De Bock, M., Decrock, E., Wang, N., Bol, M., Vinken, M., Bultynck, G., et al. (2014). The dual face of connexin-based astroglial $\mathrm{Ca}^{2+}$ communication: a key player in brain physiology and a prime target in pathology. Biochim. Biophys. Acta 1843, 2211-2232. doi: 10.1016/j.bbamcr.2014.04.016

De Pina-Benabou, M. H., Srinivas, M., Spray, D. C., and Scemes, E. (2001). Calmodulin kinase pathway mediates the $\mathrm{K}^{+}$-induced increase in Gap junctional communication between mouse spinal cord astrocytes. J. Neurosci. $21,6635-6643$.

Dere, E., De Souza-Silva, M. A., Frisch, C., Teubner, B., Sohl, G., Willecke, K., et al. (2003). Connexin30-deficient mice show increased emotionality and decreased rearing activity in the open-field along with neurochemical changes. Eur. J. Neurosci. 18, 629-638. doi: 10.1046/j.1460-9568.2003.02784.x

Dermietzel, R., Hertberg, E. L., Kessler, J. A., and Spray, D. C. (1991). Gap junctions between cultured astrocytes: immunocytochemical, molecular, and electrophysiological analysis. J. Neurosci. 11, 1421-1432.

Duchêne, A., Perier, M., Zhao, Y., Liu, X., Thomasson, J., Chauveau, F., et al. (2016). Impact of astroglial connexins on modafinil pharmacological properties. Sleep 39, 1283-1292. doi: 10.5665/sleep.5854

Duffy, H. S., John, G. R., Lee, S. C., Brosnan, C. F., and Spray, D. C. (2000). Reciprocal regulation of the junctional proteins claudin- 1 and connexin 43 by interleukin-1beta in primary human fetal astrocytes. J. Neurosci. 20, RC114.

Enkvist, M. O., and McCarthy, K. D. (1994). Astroglial gap junction communication is increased by treatment with either glutamate or high $\mathrm{K}^{+}$concentration. J. Neurochem. 62, 489-495. doi: 10.1046/j.1471-4159.1994.62020489.x

Escartin, C., and Rouach, N. (2013). Astroglial networking contributes to neurometabolic coupling. Front. Neuroenergetics 5:4. doi: $10.3389 /$ fnene.2013.00004

Fatemi, S. H., Folsom, T. D., Reutiman, T. J., and Lee, S. (2008a). Expression of astrocytic markers aquaporin 4 and connexin 43 is altered in brains of subjects with autism. Synapse 62, 501-507. doi: 10.1002/syn.20519

Fatemi, S. H., Folsom, T. D., Reutiman, T. J., Pandian, T., Braun, N. N., and Haug, K. (2008b). Chronic psychotropic drug treatment causes differential expression of connexin 43 and GFAP in frontal cortex of rats. Schizophr. Res. 104, 127-134. doi: 10.1016/j.schres.2008.05.016

Faustmann, P. M., Haase, C. G., Romberg, S., Hinkerohe, D., Szlachta, D., Smikalla, D., et al. (2003). Microglia activation influences dye coupling and Cx43 expression of the astrocytic network. Glia 42, 101-108. doi: 10.1002/glia.10141

Fellin, T., Ellenbogen, J. M., De Pitta, M., Ben-Jacob, E., and Halassa, M. M. (2012). Astrocyte regulation of sleep circuits: experimental and modeling perspectives. Front. Comput. Neurosci. 6:65. doi: 10.3389/fncom.2012.00065

Finnerup, N. B., Attal, N., Haroutounian, S., McNicol, E., Baron, R., Dworkin, R. H., et al. (2015). Pharmacotherapy for neuropathic pain in adults: a systematic review and meta-analysis. Lancet Neurol. 14, 162-173. doi: 10.1016/S1474-4422(14)70251-0

Fischer, G., and Kettenmann, H. (1985). Cultured astrocytes form a syncytium after maturation. Exp. Cell Res. 159, 273-279. doi: 10.1016/S0014-4827(85) 80001-X

Franco-Perez, J., Ballesteros-Zebadua, P., Fernandez-Figueroa, E. A., RuizOlmedo, I., Reyes-Grajeda, P., and Paz, C. (2012). Sleep deprivation and sleep recovery modifies connexin 36 and connexin 43 protein levels in rat brain. Neuroreport 23, 103-107. doi: 10.1097/WNR.0b013e32834e8fcb

Frisch, C., Theis, M., De Souza Silva, M. A., Dere, E., Sohl, G., Teubner, B., et al. (2003). Mice with astrocyte-directed inactivation of connexin 43 exhibit increased exploratory behaviour, impaired motor capacities, and changes in brain acetylcholine levels. Eur. J. Neurosci. 18, 2313-2318. doi: 10.1046/j.1460-9568.2003.02971.x

Giaume, C. (2010). Astroglial wiring is adding complexity to neuroglial networking. Front. Neuroenergetics 2:129. doi: 10.3389/fnene.2010.00129
Giaume, C., and Liu, X. (2012). From a glial syncytium to a more restricted and specific glial networking. J. Physiol. Paris 106, 34-39. doi: 10.1016/j.jphysparis.2011.09.001

Giaume, C., and McCarthy, K. D. (1996). Control of gap-junctional communication in astrocytic networks. Trends Neurosci. 19, 319-325. doi: 10.1016/0166-2236(96)10046-1

Giaume, C., Fromaget, C., el Aoumari, A., Cordier, J., Glowinski, J., and Gros, D. (1991a). Gap junctions in cultured astrocytes: single-channel currents and characterization of channel-forming protein. Neuron 6, 133-143. doi: 10.1016/0896-6273(91)90128-M

Giaume, C., Koulakoff, A., Roux, L., Holcman, D., and Rouach, N. (2010). Astroglial networks: a step further in neuroglial and gliovascular interactions. Nat. Rev. Neurosci. 11, 87-99. doi: 10.1038/nrn2757

Giaume, C., Leybaert, L., Naus, C. C., and Sáez, J. C. (2013). Connexin and pannexin hemichannels in brain glial cells: properties, pharmacology, and roles. Front. Pharmacol. 4:88. doi: 10.3389/fphar.2013.00088

Giaume, C., Marin, P., Cordier, J., Glowinski, J., and Premont, J. (1991b). Adrenergic regulation of intercellular communications between cultured striatal astrocytes from the mouse. Proc. Natl. Acad. Sci. U.S.A. 88, 5577-5581. doi: $10.1073 /$ pnas.88.13.5577

Griemsmann, S., Hoft, S. P., Bedner, P., Zhang, J., von Staden, E., Beinhauer, A., et al. (2015). Characterization of panglial gap junction networks in the thalamus, neocortex, and hippocampus reveals a unique population of glial cells. Cereb. Cortex 25, 3420-3433. doi: 10.1093/cercor/bhu157

Haghikia, A., Ladage, K., Hinkerohe, D., Vollmar, P., Heupel, K., Dermietzel, R., et al. (2008). Implications of antiinflammatory properties of the anticonvulsant drug levetiracetam in astrocytes. J. Neurosci. Res. 86, 1781-1788. doi: 10.1002/jnr.21639

Hamon, M., Kayser, V., and Bourgoin, S. (2008). [Neuropathic pain. Physiopathological mechanisms and therapeutic perspectives]. Bull. Acad. Natl. Med. 192, 921-926; discussion: 926-928.

Han, X., Chen, M., Wang, F., Windrem, M., Wang, S., Shanz, S., et al. (2013). Forebrain engraftment by human glial progenitor cells enhances synaptic plasticity and learning in adult mice. Cell Stem Cell 12, 342-353. doi: 10.1016/j.stem.2012.12.015

Han, Y., Yu, H. X., Sun, M. L., Wang, Y., Xi, W., and Yu, Y. Q. (2014). Astrocyterestricted disruption of connexin-43 impairs neuronal plasticity in mouse barrel cortex. Eur. J. Neurosci. 39, 35-45. doi: 10.1111/ejn.12394

Hanani, M., Huang, T. Y., Cherkas, P. S., Ledda, M., and Pannese, E. (2002). Glial cell plasticity in sensory ganglia induced by nerve damage. Neuroscience 114, 279-283. doi: 10.1016/S0306-4522(02)00279-8

He, D. S., and Burt, J. M. (2000). Mechanism and selectivity of the effects of halothane on gap junction channel function. Circ. Res. 86, E104-E109. doi: 10.1161/01.RES.86.11.e104

Houades, V., Koulakoff, A., Ezan, P., Seif, I., and Giaume, C. (2008). Gap junctionmediated astrocytic networks in the mouse barrel cortex. J. Neurosci. 28, 5207-5217. doi: 10.1523/JNEUROSCI.5100-07.2008

Houades, V., Rouach, N., Ezan, P., Kirchhoff, F., Koulakoff, A., and Giaume, C. (2006). Shapes of astrocyte networks in the juvenile brain. Neuron Glia Biol. 2, 3-14. doi: 10.1017/S1740925X06000081

Hubbard, J. A., and Binder, D. K. (2016). "History of astrocytes," in Astrocytes and Epilepsy (San Diego, CA: Academic Press), 1-38.

Jeanson, T., Duchêne, A., Richard, D., Bourgoin, S., Picoli, C., Ezan, P., et al. (2016a). Potentiation of amitriptyline anti-hyperalgesic-like action by astroglial connexin 43 inhibition in neuropathic rats. Sci. Rep. 6:38766. doi: 10.1038/srep38766

Jeanson, T., Pondaven, A., Ezan, P., Mouthon, F., Charvériat, M., and Giaume, C. (2016b). Antidepressants impact connexin 43 channel functions in astrocytes. Front. Cell. Neurosci. 9:495. doi: 10.3389/fncel.2015.00495

Kang, N., Xu, J., Xu, Q., Nedergaard, M., and Kang, J. (2005). Astrocytic glutamate release-induced transient depolarization and epileptiform discharges in hippocampal CA1 pyramidal neurons. J. Neurophysiol. 94, 4121-4130. doi: 10.1152/jn.00448.2005

Kettenmann, H., and Ransom, B. R. (1988). Electrical coupling between astrocytes and between oligodendrocytes studied in mammalian cell cultures. Glia 1, 64-73. doi: 10.1002/glia.440010108

Kettenmann, H., and Verkhratsky, A. (2008). Neuroglia: the 150 years after. Trends Neurosci. 31, 653-659. doi: 10.1016/j.tins.2008.09.003 
Kofuji, P., and Newman, E. A. (2004). Potassium buffering in the central nervous system. Neuroscience 129, 1045-1056. doi: 10.1016/j.neuroscience.2004.06.008

Koulakoff, A., Ezan, P., and Giaume, C. (2008). Neurons control the expression of connexin 30 and connexin 43 in mouse cortical astrocytes. Glia 56, 1299-1311. doi: $10.1002 /$ glia.20698

Koulakoff, A., Meme, W., Calvo, C. F., Ezan, P., Rouach, N., and Giaume, C. (2003). Neurons and brain macrophages regulate connexin expression in cultured astrocytes. Cell Commun. Adhes. 10, 407-411. doi: 10.1080/cac.10.4-6.407.411

Kunzelmann, P., Schroder, W., Traub, O., Steinhauser, C., Dermietzel, R., and Willecke, K. (1999). Late onset and increasing expression of the gap junction protein connexin 30 in adult murine brain and long-term cultured astrocytes. Glia 25, 111-119. doi: 10.1002/(SICI)1098-1136(19990115)25:2<111 ::AID-GLIA2>3.0.CO;2-I

Leybaert, L. (2005). Neurobarrier coupling in the brain: a partner of neurovascular and neurometabolic coupling? J. Cereb. Blood Flow Metab. 25, 2-16. doi: $10.1038 /$ si.jcbfm. 9600001

Leybaert, L., and Sanderson, M. J. (2012). Intercellular $\mathrm{Ca}^{2+}$ waves: mechanisms and function. Physiol. Rev. 92, 1359-1392. doi: 10.1152/physrev.00029.2011

Leybaert, L., Paemeleire, K., Strahonja, A., and Sanderson, M. J. (1998). Inositoltrisphosphate-dependent intercellular calcium signaling in and between astrocytes and endothelial cells. Glia 24, 398-407.

Li, W. E., and Nagy, J. I. (2000). Activation of fibres in rat sciatic nerve alters phosphorylation state of connexin- 43 at astrocytic gap junctions in spinal cord: evidence for junction regulation by neuronal-glial interactions. Neuroscience 97, 113-123. doi: 10.1016/S0306-4522(00)00032-4

Liebmann, M., Stahr, A., Guenther, M., Witte, O. W., and Frahm, C. (2013). Astrocytic $\mathrm{Cx} 43$ and $\mathrm{Cx} 30$ differentially modulate adult neurogenesis in mice. Neurosci. Lett. 545, 40-45. doi: 10.1016/j.neulet.2013.04.013

Liu, X., Gangoso, E., Yi, C., Jeanson, T., Kandelman, S., Mantz, J., et al. (2016). General anesthetics have differential inhibitory effects on gap junction channels and hemichannels in astrocytes and neurons. Glia 64, 524-536. doi: $10.1002 /$ glia. 22946

Liu, X., Petit, J. M., Ezan, P., Gyger, J., Magistretti, P., and Giaume, C. (2013). The psychostimulant modafinil enhances gap junctional communication in cortical astrocytes. Neuropharmacology 75, 533-538. doi: 10.1016/j.neuropharm.2013.04.019

$\mathrm{Lu}$, J., and Chen, M. (2016). Glial gap junctions boost modafinil action on arousal. Sleep 39, 1175-1177. doi: 10.5665/sleep.5824

Lutz, S. E., Zhao, Y., Gulinello, M., Lee, S. C., Raine, C. S., and Brosnan, C. F. (2009). Deletion of astrocyte connexins 43 and 30 leads to a dysmyelinating phenotype and hippocampal CA1 vacuolation. J. Neurosci. 29, 7743-7752. doi: 10.1523/JNEUROSCI.0341-09.2009

Lynn, B. D., Tress, O., May, D., Willecke, K., and Nagy, J. I. (2011). Ablation of connexin30 in transgenic mice alters expression patterns of connexin26 and connexin32 in glial cells and leptomeninges. Eur. J. Neurosci. 34, 1783-1793. doi: 10.1111/j.1460-9568.2011.07900.x

Magistretti, P. J. (2006). Neuron-glia metabolic coupling and plasticity. J. Exp. Biol. 209(Pt 12), 2304-2311. doi: 10.1242/jeb.02208

Mantz, J., Cordier, J., and Giaume, C. (1993). Effects of general anesthetics on intercellular communications mediated by gap junctions between astrocytes in primary culture. Anesthesiology 78, 892-901. doi: 10.1097/00000542-199305000-00014

Marrero, H., and Orkand, R. K. (1996). Nerve impulses increase glial intercellular permeability. Glia 16, 285-289. doi: 10.1002/(SICI)1098-1136 (199603)16:3<285::AID-GLIA11>3.0.CO;2-W

M’Dahoma, S., Barthelemy, S., Tromilin, C., Jeanson, T., Viguier, F., Michot, B., et al. (2015). Respective pharmacological features of neuropathic-like pain evoked by intrathecal BDNF versus sciatic nerve ligation in rats. Eur. Neuropsychopharmacol. 25, 2118-2130. doi: 10.1016/j.euroneuro.2015.07.026

Même, W., Calvo, C. F., Froger, N., Ezan, P., Amigou, E., Koulakoff, A., et al. (2006). Proinflammatory cytokines released from microglia inhibit gap junctions in astrocytes: potentiation by beta-amyloid. FASEB J. 20, 494-496. doi: 10.1096/fj.05-4297fje

Miguel-Hidalgo, J. J., Wilson, B. A., Hussain, S., Meshram, A., Rajkowska, G., and Stockmeier, C. A. (2014). Reduced connexin 43 immunolabeling in the orbitofrontal cortex in alcohol dependence and depression. J. Psychiatr. Res. 55, 101-109. doi: 10.1016/j.jpsychires.2014.04.007
Minzenberg, M. J., and Carter, C. S. (2008). Modafinil: a review of neurochemical actions and effects on cognition. Neuropsychopharmacology 33, 1477-1502. doi: 10.1038/sj.npp.1301534

Moore, L. K., and Burt, J. M. (1995). Gap junction function in vascular smooth muscle: influence of serotonin. Am. J. Physiol. 269(4 Pt 2), H1481-H1489.

Morioka, N., Suekama, K., Zhang, F. F., Kajitani, N., Hisaoka-Nakashima, K., Takebayashi, M., et al. (2014). Amitriptyline up-regulates connexin43gap junction in rat cultured cortical astrocytes via activation of the p38 and c-Fos/AP-1 signalling pathway. Br. J. Pharmacol. 171, 2854-2867. doi: $10.1111 /$ bph.12614

Mostafavi, H., Khaksarian, M., Joghataei, M. T., Hassanzadeh, G., Soleimani, M., Eftekhari, S., et al. (2014). Fluoxetin upregulates connexin 43 expression in astrocyte. Basic Clin. Neurosci. 5, 74-79.

Muller, T., Moller, T., Neuhaus, J., and Kettenmann, H. (1996). Electrical coupling among Bergmann glial cells and its modulation by glutamate receptor activation. Glia 17, 274-284. doi: 10.1002/(SICI)1098-1136(199608) 17:4<274::AID-GLIA2>3.0.CO;2-\#

Mylvaganam, S., Ramani, M., Krawczyk, M., and Carlen, P. L. (2014). Roles of gap junctions, connexins, and pannexins in epilepsy. Front. Physiol. 5:172. doi: $10.3389 /$ fphys.2014.00172

Nagy, C., Torres-Platas, S. G., Mechawar, N., and Turecki, G. (2017). Repression of astrocytic connexins in cortical and subcortical brain regions and prefrontal enrichment of $\mathrm{H} 3 \mathrm{~K} 9 \mathrm{me} 3$ in depression and suicide. Int. J. Neuropsychopharmacol. 20, 50-57. doi: 10.1093/ijnp/pyw071

Nagy, J. I., and Rash, J. E. (2000). Connexins and gap junctions of astrocytes and oligodendrocytes in the CNS. Brain Res. Brain Res. Rev. 32, 29-44. doi: 10.1016/S0165-0173(99)00066-1

Nagy, J. I., Dudek, F. E., and Rash, J. E. (2004). Update on connexins and gap junctions in neurons and glia in the mammalian nervous system. Brain Res. Brain Res. Rev. 47, 191-215. doi: 10.1016/j.brainresrev.2004.05.005

Nagy, J. I., Patel, D., Ochalski, P. A., and Stelmack, G. L. (1999). Connexin30 in rodent, cat and human brain: selective expression in gray matter astrocytes, co-localization with connexin 43 at gap junctions and late developmental appearance. Neuroscience 88, 447-468. doi: 10.1016/S0306-4522(98)00191-2

Naus, C. C., and Giaume, C. (2016). Bridging the gap to therapeutic strategies based on connexin/pannexin biology. J. Transl. Med. 14, 330. doi: 10.1186/s12967-016-1089-0

Naus, C. C., Bechberger, J. F., Zhang, Y., Venance, L., Yamasaki, H., Juneja, S. C., et al. (1997). Altered gap junctional communication, intercellular signaling, and growth in cultured astrocytes deficient in connexin 43. J. Neurosci. Res. 49, 528-540. doi: 10.1002/(SICI)1097-4547(19970901) 49:5<528::AID-JNR3>3.0.CO;2-D

Niu, J., Li, T., Yi, C., Huang, N., Koulakoff, A., Weng, C., et al. (2016). Connexinbased channels contribute to metabolic pathways in the oligodendroglial lineage. J. Cell Sci. 129, 1902-1914. doi: 10.1242/jcs.178731

Orellana, J. A., and Stehberg, J. (2014). Hemichannels: new roles in astroglial function. Front. Physiol. 5:193. doi: 10.3389/fphys.2014.00193

Orellana, J. A., Palacios-Prado, N., and Sáez, J. C. (2006). Chlorpromazine reduces the intercellular communication via gap junctions in mammalian cells. Toxicol. Appl. Pharmacol. 213, 187-197. doi: 10.1016/j.taap.2005.10.011

Orellana, J. A., Sáez, P. J., Shoji, K. F., Schalper, K. A., Palacios-Prado, N., Velarde, V., et al. (2009). Modulation of brain hemichannels and gap junction channels by pro-inflammatory agents and their possible role in neurodegeneration. Antioxid. Redox Signal. 11, 369-399. doi: 10.1089/ars.2008.2130

Orthmann-Murphy, J. L., Freidin, M., Fischer, E., Scherer, S. S., and Abrams, C. K. (2007). Two distinct heterotypic channels mediate gap junction coupling between astrocyte and oligodendrocyte connexins. J. Neurosci. 27, 13949-13957. doi: 10.1523/JNEUROSCI.3395-07.2007

Pannasch, U., and Rouach, N. (2013). Emerging role for astroglial networks in information processing: from synapse to behavior. Trends Neurosci. 36, 405-417. doi: 10.1016/j.tins.2013.04.004

Pannasch, U., Derangeon, M., Chever, O., and Rouach, N. (2012). Astroglial gap junctions shape neuronal network activity. Commun. Integr. Biol. 5, 248-254. doi: $10.4161 /$ cib.19410

Pannasch, U., Freche, D., Dallerac, G., Ghezali, G., Escartin, C., Ezan, P., et al. (2014). Connexin 30 sets synaptic strength by controlling astroglial synapse invasion. Nat. Neurosci. 17, 549-558. doi: 10.1038/nn.3662 
Pannasch, U., Vargova, L., Reingruber, J., Ezan, P., Holcman, D., Giaume, C., et al. (2011). Astroglial networks scale synaptic activity and plasticity. Proc. Natl. Acad. Sci. U.S.A. 108, 8467-8472. doi: 10.1073/pnas.1016650108

Pellerin, L., Bouzier-Sore, A. K., Aubert, A., Serres, S., Merle, M., Costalat, R., et al. (2007). Activity-dependent regulation of energy metabolism by astrocytes: an update. Glia 55, 1251-1262. doi: 10.1002/glia.20528

Perez Velazquez, J. L., Frantseva, M., Naus, C. C., Bechberger, J. F., Juneja, S. C., Velumian, A., et al. (1996). Development of astrocytes and neurons in cultured brain slices from mice lacking connexin43. Brain Res. Dev. Brain Res. 97, 293-296. doi: 10.1016/S0165-3806(96)00156-3

Petit, J. M., and Magistretti, P. J. (2016). Regulation of neuron-astrocyte metabolic coupling across the sleep-wake cycle. Neuroscience 323, 135-156. doi: 10.1016/j.neuroscience.2015.12.007

Picoli, C., Nouvel, V., Aubry, F., Reboul, M., Duchene, A., Jeanson, T., et al. (2012). Human connexin channel specificity of classical and new gap junction inhibitors. J. Biomol. Screen. 17, 1339-1347. doi: 10.1177/1087057112452594

Poskanzer, K. E., and Yuste, R. (2011). Astrocytic regulation of cortical UP states. Proc. Natl. Acad. Sci. U.S.A. 108, 18453-18458. doi: 10.1073/pnas.1112378108

Poskanzer, K. E., and Yuste, R. (2016). Astrocytes regulate cortical state switching in vivo. Proc. Natl. Acad. Sci. U.S.A. 113, E2675-E2684. doi: 10.1073/pnas.1520759113

Quesseveur, G., Portal, B., Basile, J. A., Ezan, P., Mathou, A., Halley, H., et al. (2015). Attenuated levels of hippocampal connexin 43 and its phosphorylation correlate with antidepressant- and anxiolytic-like activities in mice. Front. Cell. Neurosci. 9:490. doi: 10.3389/fncel.2015.00490

Ransom, B. R., and Sontheimer, H. (1992). "Cell-cell coupling demonstrated by intracellular injection of the fluorescent dye lucifer yellow," in Electrophysiological Methods for In vitro Studies in Vertebrate Neurobiology, eds H. Kettenmann and R. Grantyn (New York, NY: Wiley-Liss), 336-342.

Rela, L., and Szczupak, L. (2007). In situ characterization of a rectifying electrical junction. J. Neurophysiol. 97, 1405-1412. doi: 10.1152/jn.00973.2006

Retamal, M. A., Froger, N., Palacios-Prado, N., Ezan, P., Sáez, P. J., Sáez, J. C., et al. (2007). Cx43 hemichannels and gap junction channels in astrocytes are regulated oppositely by proinflammatory cytokines released from activated microglia. J. Neurosci. 27, 13781-13792. doi: 10.1523/JNEUROSCI.2042-07.2007

Rohlmann, A., Laskawi, R., Hofer, A., Dobo, E., Dermietzel, R., and Wolff, J. R. (1993). Facial nerve lesions lead to increased immunostaining of the astrocytic gap junction protein (connexin 43 ) in the corresponding facial nucleus of rats. Neurosci. Lett. 154, 206-208. doi: 10.1016/0304-3940(93)90208-3

Rouach, N., Avignone, E., Meme, W., Koulakoff, A., Venance, L., Blomstrand, F., et al. (2002a). Gap junctions and connexin expression in the normal and pathological central nervous system. Biol. Cell 94, 457-475. doi: 10.1016/S0248-4900(02)00016-3

Rouach, N., Calvo, C. F., Glowinski, J., and Giaume, C. (2002b). Brain macrophages inhibit gap junctional communication and downregulate connexin 43 expression in cultured astrocytes. Eur. J. Neurosci. 15, 403-407. doi: 10.1046/j.0953-816x.2001.01868.x

Rouach, N., Glowinski, J., and Giaume, C. (2000). Activity-dependent neuronal control of gap-junctional communication in astrocytes. J. Cell Biol. 149, 1513-1526. doi: 10.1083/jcb.149.7.1513

Rouach, N., Koulakoff, A., Abudara, V., Willecke, K., and Giaume, C. (2008). Astroglial metabolic networks sustain hippocampal synaptic transmission. Science 322, 1551-1555. doi: 10.1126/science.1164022

Rouach, N., Koulakoff, A., and Giaume, C. (2004). Neurons set the tone of gap junctional communication in astrocytic networks. Neurochem. Int. 45, 265-272. doi: 10.1016/j.neuint.2003.07.004

Rouach, N., Tence, M., Glowinski, J., and Giaume, C. (2002c). Costimulation of N-methyl-D-aspartate and muscarinic neuronal receptors modulates gap junctional communication in striatal astrocytes. Proc. Natl. Acad. Sci. U.S.A. 99, 1023-1028. doi: 10.1073/pnas.022257499
Roux, L., Benchenane, K., Rothstein, J. D., Bonvento, G., and Giaume, C. (2011). Plasticity of astroglial networks in olfactory glomeruli. Proc. Natl. Acad. Sci. U.S.A. 108, 18442-18446. doi: 10.1073/pnas.1107386108

Rozental, R., Morales, M., Mehler, M. F., Urban, M., Kremer, M., Dermietzel, R., et al. (1998). Changes in the properties of gap junctions during neuronal differentiation of hippocampal progenitor cells. J. Neurosci. 18, 1753-1762.

Scemes, E., and Giaume, C. (2006). Astrocyte calcium waves: what they are and what they do. Glia 54, 716-725. doi: 10.1002/glia.20374

Scemes, E., Dermietzel, R., and Spray, D. C. (1998). Calcium waves between astrocytes from Cx43 knockout mice. Glia 24, 65-73.

Serrano, A., Haddjeri, N., Lacaille, J. C., and Robitaille, R. (2006). GABAergic network activation of glial cells underlies hippocampal heterosynaptic depression. J. Neurosci. 26, 5370-5382. doi: 10.1523/JNEUROSCI.5255-05.2006

Serrano, A., Robitaille, R., and Lacaille, J. C. (2008). Differential NMDAdependent activation of glial cells in mouse hippocampus. Glia 56, 1648-1663. doi: $10.1002 /$ glia.20717

Steinhauser, C., Grunnet, M., and Carmignoto, G. (2016). Crucial role of astrocytes in temporal lobe epilepsy. Neuroscience 323, 157-169. doi: 10.1016/j.neuroscience.2014.12.047

Sun, J. D., Liu, Y., Yuan, Y. H., Li, J., and Chen, N. H. (2012). Gap junction dysfunction in the prefrontal cortex induces depressive-like behaviors in rats. Neuropsychopharmacology 37, 1305-1320. doi: 10.1038/npp.2011.319

Theis, M., Jauch, R., Zhuo, L., Speidel, D., Wallraff, A., Doring, B., et al. (2003). Accelerated hippocampal spreading depression and enhanced locomotory activity in mice with astrocyte-directed inactivation of connexin43. J. Neurosci. 23, 766-776.

Venance, L., Cordier, J., Monge, M., Zalc, B., Glowinski, J., and Giaume, C. (1995). Homotypic and heterotypic coupling mediated by gap junctions during glial cell differentiation in vitro. Eur. J. Neurosci. 7, 451-461. doi: 10.1111/j.1460-9568.1995.tb00341.x

Verkhratsky, A., and Nedergaard, M. (2016). The homeostatic astroglia emerges from evolutionary specialization of neural cells. Philos. Trans. R. Soc. Lond. B Biol. Sci. 371:20150428. doi: 10.1098/rstb.2015.0428

Virchow, R. (1859). Die Cellularpathologie in Ihrer Begründung auf Physiologische und Pathologische Gewebelehre. Berlin: Verlag von August Hirschwald.

Wallraff, A., Kohling, R., Heinemann, U., Theis, M., Willecke, K., and Steinhauser, C. (2006). The impact of astrocytic gap junctional coupling on potassium buffering in the hippocampus. J. Neurosci. 26, 5438-5447. doi: 10.1523/JNEUROSCI.0037-06.2006

Wasseff, S. K., and Scherer, S. S. (2011). Cx32 and Cx47 mediate oligodendrocyte:astrocyte and oligodendrocyte:oligodendrocyte gap junction coupling. Neurobiol. Dis. 42, 506-513. doi: 10.1016/j.nbd.2011.03.003

Yamamuro, K., Kimoto, S., Rosen, K. M., Kishimoto, T., and Makinodan, M. (2015). Potential primary roles of glial cells in the mechanisms of psychiatric disorders. Front. Cell. Neurosci. 9:154. doi: 10.3389/fncel.2015. 00154

Conflict of Interest Statement: MC is a co-founder and full-time employee of Theranexus.

The other authors declare that the research was conducted in the absence of any commercial or financial relationships that could be construed as a potential conflict of interest.

Copyright (C) 2017 Charvériat, Naus, Leybaert, Sáez and Giaume. This is an openaccess article distributed under the terms of the Creative Commons Attribution License (CC BY). The use, distribution or reproduction in other forums is permitted, provided the original author(s) or licensor are credited and that the original publication in this journal is cited, in accordance with accepted academic practice. No use, distribution or reproduction is permitted which does not comply with these terms. 